\title{
Balkanologie
}

Balkanologie Revue d'études pluridisciplinaires

Vol. IX, n' 1-2 | 2005

Volume IX Numéro 1-2

\section{Redžić [Enver], Bosnia and Herzegovineg in the Second} World War,

London / New York: Frank Cass, 2005, xi + 250 p.

Philippe Gelez

\section{(2) OpenEdition}

\section{Journals}

Édition électronique

URL : http://journals.openedition.org/balkanologie/2012

DOI : 10.4000/balkanologie.2012

ISSN : 1965-0582

\section{Éditeur}

Association française d'études sur les Balkans (Afebalk)

Édition imprimée

Date de publication : 1 décembre 2005

ISSN : 1279-7952

\section{Référence électronique}

Philippe Gelez, «Redžić [Enver], Bosnia and Herzegovineg in the Second World War, », Balkanologie [En ligne], Vol. IX, n 1-2 | 2005, mis en ligne le 14 janvier 2010, consulté le 17 décembre 2020. URL : http:// journals.openedition.org/balkanologie/2012 ; DOI : https://doi.org/10.4000/balkanologie.2012

Ce document a été généré automatiquement le 17 décembre 2020.

(c) Tous droits réservés 


\section{Redžić [Enver], Bosnia and Herzegovineg in the Second World War,}

London / New York : Frank Cass, 2005, xi + 250 p.

Philippe Gelez

\section{RÉFÉRENCE}

Redžić [Enver], Bosnia and Herzegovineg in the Second World War, London / New York :

Frank Cass, 2005, xi $+250 \mathrm{p}$.

1 Voici la traduction, sous le même titre et avec sensiblement le même contenu, d'un livre qu'E. Redžić (1915-) publia à Sarajevo en 1998². Le lecteur ignorant le bosniaque tient ainsi entre les mains un ouvrage en langue "accessible" qui reflète avec exactitude l'historiographie de l'ex-Yougoslavie. Celle-ci est typique en raison de la méthode avec laquelle sont traités les documents historiques. En effet, les historiens yougoslaves s'intéressaient généralement à l'histoire des idées; plutôt que d'exposer les faits, ils préféraient décrire les intentions qui animaient les personnages marquants d'une époque donnée, en ignorant trop souvent les conséquences concrètes de ces intentions. Cette approche pouvait mener ou bien à un exposé trop vague, où les dates étaient rares et les événements plus rares encore, ou bien à la distorsion des faits sous la pression des idées. E. Redžić, formé à cette école hégélienne, nous retrace ici l'histoire intentionnelle, idéelle, de la Bosnie-Herzégovine durant la Seconde Guerre mondiale, avec quelques maigres décrochages dans la réalité statistique.

2 Néanmoins, outre sa maîtrise du sujet, il faut relever le travail important qu'il a effectué en archives (Sarajevo, Zagreb, Belgrade, Berlin), ce qui fait que ce livre est instructif à bien des égards. Il distingue cinq groupes qui s'arrachent le pouvoir en Bosnie-Herzégovine entre 1941 et 1945: tour à tour les Puissances de l'Axe (concrètement, Allemands et Italiens), l'État Indépendant de Croatie (NDH), les Tchetniks, les autonomistes musulmans et les Partisans. Son exposé tire toute son appréciable clarté de ce qu'il étudie une à une chacune de ces formations, tout en les 
examinant constamment dans leurs interactions avec les autres. Ce détour rhétorique, qui a l'inconvénient de parfois prêter à la répétition, permet d'envisager la période comme dynamique.

On voit ainsi les alliances se faire et se défaire; nul ne frémit à l'idée de s'allier avec l'adversaire pour combattre l'ennemi commun. Redžić sort de l'opposition simpliste entre «fascistes » et « héros communistes » : il montre que les combats furent affaire plus souvent de circonstances que d'idéologie, et que les victoires des uns furent souvent obtenues par les querelles des autres entre eux. Les motivations de tous ces groupes sont diverses: celle d'assurer son pouvoir pour les Allemands, celle de le légitimer pour les Oustachis, celle de faire valoir un droit ethnique pour les Tchetniks, celle de faire triompher un droit historique pour les musulmans ou une idéologie pour les communistes.

4 À propos des Tchetniks et des musulmans, notamment, on peut cependant se demander si la résistance sur le terrain convergeait véritablement autour d'idéaux bien définis. D'une part, l'isolement géographique des différents acteurs ne permettait pas une communication fluide; Redžić ne manque pas de le noter, mais n'en tire pas les conséquences. Or, la conduite de bien des officiers a été dictée par un chaos d'intérêts locaux et individuels, et c'est principalement ce fait qui peut expliquer les renversements d'alliance perpétuels. Notre auteur ne prend pas suffisamment en considération esprit de revanche et instinct de survie.

D'autre part, Redžić se plaît à penser que les musulmans désiraient une autonomie politique; mais en est-on bien sûr? En établissant trop rapidement leur prise de distance vis-à-vis du régime de Pavelić, le chef des Oustachis, il ne rend pas suffisamment compte du problème de leur participation à l'État Indépendant de Croatie. Cette position reflète celle des historiens «bochniaques » actuels, pour qui les musulmans ont toujours aspiré à l'indépendance et, lorsqu'ils ne disposaient pas des conditions pour y parvenir, ont réclamé une autonomie au sein de l'État auquel leur région appartenait.

6 Il semble ainsi qu'il y ait dans ce livre des généralisations abusives, que seule une étude de détail aurait évitées. Ce qui intéresse Redžić, c'est plutôt de créer une dialectique historique dans son exposé : il part des vaincus pour aller vers les vainqueurs, dans un mouvement semble-t-il nécessaire. Il est indéniable qu'à la fin 1944, Tito apparaît comme l'irrésistible héros de ce conflit; Redžić, qui combattit lui-même à ses côtés, ne se fait pas faute de reprendre la présentation traditionnelle du rôle des Partisans. Mais il ne met pas en valeur le fait que Tito a remporté la partie moins par lui-même que grâce à l'aide des Alliés et au recul progressif de Hitler.

7 Saluons sinon la transparence de Redžić, en tout cas son courage. Quoiqu'éprouvant une sympathie marquée pour ses coreligionnaires, il n'hésite pas à souligner que les massacres commis au printemps 1941 sur les Serbes des confins bosniaques par les Oustachis, le furent en bonne partie par les musulmans appartenant à cette armée. C'est très courageux de sa part: il affronte une opinion nationale et internationale persuadée que les musulmans sont les victimes éternelles de l'orthodoxie serbe, depuis la bataille de Kosovo en 1389 jusqu'à 1995. Ce courage est d'ailleurs inutile : en insistant sur le fait que 750000 Serbes périrent alors (voir la note 69, p. 113), Redžić montre qu'il n'a pas lu les livres de Vladimir Žerjavić et Bogoljub Kočovic ${ }^{2}$, ce que confirme l'inspection des notes (il n'y a pas de bibliographie). On pourrait interpréter cette absence de deux manières : ou bien les faits l'intéressent moins que les les idées; ou 
bien il n'a pas voulu entrer dans des polémiques de chiffres, prétextes à un discours victimaire, polémiques que le dernier conflit a ravivées et qui ont connu un rebondissement inattendu au début de 2006 avec les déclarations fracassantes de Mirsad Tokača sur le nombre de victimes du conflit de 1992-1995.

Cette version anglaise a été effectuée par Aida Vidan, lectrice de langues et littératures slaves à l'Université de Harvard, et préfacée par Robert J. Donia, spécialiste américain de la Bosnie-Herzégovine. Il n'y aurait pas grand chose à dire de ces personnalités tutélaires, et des buts implicites d'une telle traduction, sinon l'intérêt purement scientifique qui s'en dégage. On s'accordera donc sur son importance avec Marko Attila Hoare, qui en a publié une note de lecture dans Bosnia Report, la revue en ligne du Bosnian Institute de Londres ${ }^{3}$. Après avoir soutenu à l'Université de Yale, en 2000, une thèse intitulée Le Conflit entre Partisans et Tchetniks et les origines de l'étaticité bosniaque (The Chetnik-Partisan Conflict and the Origins of Bosnian Statehood), M. A. Hoare a écrit à plusieurs reprises sur l'histoire de la Bosnie-Herzégovine durant la Seconde Guerre mondiale ; il connaît son sujet et rend au livre d'E. Redžić tous les honneurs qui lui reviennent, tout en feignant d'en ignorer la part idéologique.

\section{NOTES}

1. Redžić (Enver), Bosna i Hercegovina u drugom svjetskom ratu, Sarajevo : OKO, 1998.

2. Le livre de Žerjavič, dont les résultats sont sensiblement identiques à ceux de Kočović, a été traduit en anglais : Žerjavič (Vladimir), Population losses in Yugoslavia : 1941 - 1945, Zagreb : Dom i svijet / Hrvatski institut za povijest, 1997. Il ramène le chiffre mythique de 1706000 "victimes du fachisme" colporté par la propagande titiste à un peu plus d'un million.

3. Bosnia Report, (43-44), janv.avr. 2005 - voir à l'adresse suivante : http ://www.bosnia.org.uk/ bosrep/re- port_format.cfm ? articleid=2984\&reportid=167. 